Texas Southern University

Digital Scholarship @ Texas Southern University

Faculty Publications

$2-5-2019$

\title{
Simultaneous LC-MS/MS analysis of simvastatin, atorvastatin, rosuvastatin and their active metabolites for plasma samples of obese patients underwent gastric bypass surgery
}

\author{
Asma El-Zailik \\ University of Houston \\ Lily K. Cheung \\ Texas Southern University \\ Yang Wang \\ University of Houston \\ Vadim Sherman \\ Houston Methodist Hospital \\ Diana S.L. Chow \\ University of Houston
}

Follow this and additional works at: https://digitalscholarship.tsu.edu/facpubs

\section{Recommended Citation}

El-Zailik, Asma; Cheung, Lily K.; Wang, Yang; Sherman, Vadim; and Chow, Diana S.L., "Simultaneous LC-MS/MS analysis of simvastatin, atorvastatin, rosuvastatin and their active metabolites for plasma samples of obese patients underwent gastric bypass surgery" (2019). Faculty Publications. 119. https://digitalscholarship.tsu.edu/facpubs/119

This Article is brought to you for free and open access by Digital Scholarship @ Texas Southern University. It has been accepted for inclusion in Faculty Publications by an authorized administrator of Digital Scholarship @ Texas Southern University. For more information, please contact haiying.li@tsu.edu. 


\title{
Simultaneous LC-MS/MS analysis of simvastatin, atorvastatin, rosuvastatin and their active metabolites for plasma samples of obese patients underwent gastric bypass surgery
}

\author{
Asma El-Zailik ${ }^{\mathrm{a}, *}$, Lily K. Cheung ${ }^{\mathrm{b}}$, Yang Wang ${ }^{\mathrm{a}}$, Vadim Sherman ${ }^{\mathrm{c}}$, Diana S.-L. Chow ${ }^{\mathrm{a}}$ \\ a Department of Pharmacological and Pharmaceutical Sciences, College of Pharmacy, University of Houston, Houston, TX, United States \\ ${ }^{\mathrm{b}}$ Department of Pharmacy Practice and Clinical Health Sciences, College of Pharmacy and Health Sciences, Texas Southern University, Houston, TX, United \\ States \\ ${ }^{\mathrm{c}}$ Department of Surgery, Houston Methodist Hospital, Houston, TX, United States
}

\section{A R T I C L E I N F O}

\section{Article history:}

Received 3 August 2018

Accepted 25 October 2018

Available online 28 October 2018

\section{Keywords:}

Simvastatin and metabolite

Atorvastatin and metabolites

Rosuvastatin

LC-MS/MS

Hyperlipidemic plasma

Obese subjects from GBS

\begin{abstract}
A B S T R A C T
Statins, HMG-CoA reductase inhibitors, are considered the first line treatment of hyperlipidemia to reduce the risk of atherosclerotic cardiovascular diseases. The prevalence of hyperlipidemia and the risk of atherosclerotic cardiovascular diseases are higher in obese patients. Published methods for the quantification of statins and their active metabolites did not test for matrix effect of or validate the method in hyperlipidemic plasma. A sensitive, specific, accurate, and reliable LC-MS/MS method for the simultaneous quantification of simvastatin (SMV), active metabolite of simvastatin acid (SMV-A), atorvastatin (ATV), active metabolites of 2-hydroxy atorvastatin (2-OH-ATV), 4-hydroxy atorvastatin (4-OH-ATV), and rosuvastatin (RSV) was developed and validated in plasma with low (52-103 mg/dl, <300 mg/dl) and high (352-403 mg/dl, >300 mg/dl) levels of triglyceride. The column used in this method was ACQUITY UPLC BEH C18 column $(2.1 \times 100 \mathrm{~mm}$ I.D., $1.7 \mu \mathrm{m})$. A gradient elution of mobile phase A $(10 \mathrm{mM}$ ammonium formate and $0.04 \%$ formic acid in water) and mobile phase B (acetonitrile) was used with a flow rate of $0.4 \mathrm{ml} / \mathrm{min}$ and run time of $5 \mathrm{~min}$. The transitions of $\mathrm{m} / z 436.3 \rightarrow 285.2$ for SMV, $\mathrm{m} / z 437.2 \rightarrow 303.2$ for SMV-A, $m / z 559.2 \rightarrow 440.3$ for ATV, $m / z 575.4 \rightarrow 440.3$ for $2-\mathrm{OH}-\mathrm{ATV}$ and $4-\mathrm{OH}-\mathrm{ATV}, \mathrm{m} / z 482.3 \rightarrow$ 258.1 for RSV, and $m / z 412.3 \rightarrow 224.2$ for fluvastatin (internal standard, IS) were determined by Selected Reaction Monitoring (SRM) method to detect transitions ions in the positive ion mode. The assay has a linear range of 0.25 (LLOQ) $-100 \mathrm{ng} / \mathrm{ml}$ for all six analytes. Accuracy (87-114\%), precision (3-13\%), matrix effect $(92-110 \%)$, and extraction recovery (88-100\%) of the assay were within the $15 \%$ acceptable limit of FDA Guidelines in variations for plasma with both low and high triglyceride levels. The method was used successfully for the quantification of SMV, ATV, RSV, and their active metabolites in human plasma samples collected for an ongoing clinical pharmacokinetic and pharmacodynamic study on patients prior to and post gastric bypass surgery (GBS).
\end{abstract}

(c) 2018 Elsevier B.V. All rights reserved.

\section{Introduction}

Statins are a class of cholesterol-lowering medications that are used for the treatment of high blood cholesterol to reduce the risk of atherosclerotic cardiovascular diseases. Statins inhibit the enzyme 3-hydroxy-3-methylgluteryl CoA reductase (HMG-CoA reductase), which is responsible for the conversion of HMG-CoA to mevalonate. This is the rate limiting step in cholesterol biosynthesis. Inhibition of cholesterol biosynthesis in the hepatocytes leads to the upregula-

\footnotetext{
* Corresponding author.

E-mail address: amel-zailik@uh.edu (A. El-Zailik).
}

tion of low density lipoprotein (LDL) receptors in cell membrane of hepatocytes to maintain cholesterol homeostasis in the liver cells. The uptake of LDL by the liver leads to a decrease in LDL levels in the plasma. The inhibition of cholesterol synthesis and the uptake of LDL from the plasma by hepatocytes from statin treatment, and the physiological degradation of cholesterol in hepatocytes leads to an overall reduction in cholesterol levels in the body [1]. According to the American Heart Association, statins are considered the first line treatment for hyperlipidemia because they are the only drug class for the treatment of hyperlipidemia that is associated with reduction in the risk of atherosclerotic cardiovascular diseases [2].

Most obese patients (about 60-70\%) suffer from hyperlipidemia with higher levels of triglycerides and cholesterol in the plasma 
[3]. Substantially higher levels of triglycerides and cholesterol in the plasma have also been found in lean subjects after consuming a heavy fatty meal [4]. Triglycerides and cholesterol are the main lipid components in plasma that contribute to matrix effect issues in LC/MS-MS analytical assays [5]. In addition, high lipid contents in the plasma may lead to undesirable effects on the assay specificity and recovery [6]. Published methods for the quantification of statins and their metabolites in human plasma are not validated for the matrix effect in plasma samples from obese subjects or hyperlipidemic plasma. Some regulatory guidelines for bioanalytical method validation such as European Medicine Agency [7], Health Canada (which follows EMA 2011 guideline), and Brazilian National Health Surveillance Agency [8] require the performance of matrix effect test in "lipemic plasma", which is plasma with high lipid contents. However, there are no specifications in these guidelines on the lipemic level tested when a bioanalytical method is validated. A study done by Mayrand-Provencher and his colleagues has concluded that a minimum triglyceride concentration of $300 \mathrm{mg} / \mathrm{dl}$ in the plasma is required to perform a "scientifically meaningful lipemic plasma test" [6].

The purpose of this study was to develop a selective and sensitive single assay that is capable of simultaneously analyzing plasma samples of different statins and their active metabolites, specifically, simvastatin (SMV) and its metabolite simvastatin acid (SMV-A), atorvastatin (ATV) and its two metabolites 2-hydroxy atorvastatin (2-OH-ATV) and 4-hydroxy atorvastatin (4-OH-ATV), and rosuvastatin (RSV). These three statins are amongst the most commonly prescribed cholesterol lowering medications [9]. In addition, validation of the method using lipemic plasma, with triglyceride levels $\geq 300 \mathrm{mg} / \mathrm{dl}$ (352-403 $\mathrm{mg} / \mathrm{dl}$ ) was performed to ensure the reliability of the assay for clinical samples from obese patients prior to and post their gastric bypass surgery. The developed method has been successfully used for the quantification of the three statins and their active metabolites in clinical samples from these obese subjects.

\section{Materials and methods}

\subsection{Chemicals and materials}

SMV, ATV, fluvastatin, triglyceride mix, and LC-MS grade acetonitrile, water, methanol, ammonium formate ( $\geq 99.0 \%$ ), and formic acid ( $\sim 98 \%)$ were purchased from Sigma-Aldrich Corp. (St. Louis, MO, USA). RSV, SMV-A, 2-OH-ATV, and 4-OH-ATV were purchased from Toronto Research Chemicals Inc. (Toronto, Ontario, Canada). Blank human plasma was purchased from Equitech-Bio, Inc. (Kerrville, TX, USA). Ethyl acetate (spectrometric grade, 99.5+\%) was purchased from Alfa Aesar (Ward Hill, MA, USA).

\subsection{Chromatographic conditions}

Chromatographic analysis was performed using an ultrahigh performance liquid chromatography system (Waters, Milford, MA, USA). SMV, SMV-A, ATV, 2-OH-ATV, 4-OH-ATV, RSV and fluvastatin (internal standard; IS) were separated on ACQUITY UPLC BEH C18 column $(2.1 \times 100 \mathrm{~mm}$ I.D., $1.7 \mu \mathrm{m})$. The mobile phases consisted of $10 \mathrm{mM}$ ammonium formate and $0.04 \%$ formic acid in water (mobile phase A) and acetonitrile (mobile phase B). A gradient elution was used for the separation as follows: $0-1 \mathrm{~min}, 30 \% \mathrm{~B} ; 1-1.5 \mathrm{~min}$, $30-60 \%$ B; $1.5-2$ min, $60-80 \%$ B; $2-2.5$ min, $80-95 \%$ B; $2.5-3$ min, $95 \%$ B; 3-3.5 min 95-80\% B; 3.5-4 min, 80\% B; 4-4.5 min, 80-60\% $\mathrm{B} ; 4.5-5 \mathrm{~min}, 60-30 \% \mathrm{~B}$. The elution was performed at a flow rate of $0.4 \mathrm{ml} / \mathrm{min}$, with injection volume of $5 \mu \mathrm{l}$, sample temperature of $20^{\circ} \mathrm{C}$, and column temperature of $40^{\circ} \mathrm{C}$.
Table 1

Compound-dependent Parameters for SMV, SMV-A, ATV, 2-OH-ATV, 4-OH-ATV, RSV, and IS in SRM Mode for LC-MS/MS Analysis.

\begin{tabular}{llllll}
\hline Analyte & Dwell Time $(\mathrm{ms})$ & $\mathrm{DP}^{\mathrm{a}}(\mathrm{V})$ & $\mathrm{EP}^{\mathrm{a}}(\mathrm{V})$ & $\mathrm{CE}^{\mathrm{a}}(\mathrm{V})$ & $\mathrm{CXP}^{\mathrm{a}}(\mathrm{V})$ \\
\hline SMV & 100 & 100 & 8 & 13 & 19 \\
SMV-A & 100 & 100 & 7 & 11 & 16 \\
ATV & 100 & 195 & 9 & 29 & 11 \\
2-OH-ATV 4-OH-ATV & 100 & 210 & 4 & 28 & 17 \\
RSV & 100 & 100 & 9 & 41 & 12 \\
IS & 100 & 130 & 7 & 40 & 35 \\
\hline
\end{tabular}

a DP, declustering potential; EP, entrance potential; CE, collision energy; CXP, collision cell exit potential.

\subsection{Mass spectrometry conditions}

LC-MS/MS analysis was performed using an API 5500-Qtrap triple quadrupole mass spectrometer (Applied Biosystem/MDS SCIEX, Framingham, MA, USA) equipped with a TurbolonSpray ${ }^{\mathrm{TM}}$ source. The concentrations of SMV, SMV-A, ATV, 2-OH-ATV, 4-OHATV, RSV and IS in plasma samples were determined by Selected Reaction Monitoring (SRM) method to detect transitions ions in the positive ion mode. The quantifications were performed with the transitions of $m / z 436.3 \rightarrow 285.2$ for SMV, $m / z 437.2 \rightarrow 303.2$ for SMV-A, $m / z 559.2 \rightarrow 440.3$ for ATV, $m / z 575.4 \rightarrow 440.3$ for 2 -OH-ATV and $4-\mathrm{OH}-\mathrm{ATV}, \mathrm{m} / z 482.3 \rightarrow 258.1$ for RSV, and $m / z 412.3 \rightarrow 224.2$ for fluvastatin (IS). The main working parameters for mass spectrometer were set as follows: ionspray voltage, $5.5 \mathrm{kV}$; ion source temperature, $500^{\circ} \mathrm{C}$; gas 1,20 psi; gas2, 20 psi; curtain gas, 20 psi, collision gas, high. Compound-dependent parameters for the analytes and the IS were set as summarized in Table 1. By using these parameters, the positive ion SRM product ion spectra for all the analytes and the IS were established as shown in Fig. 1.

\subsection{Preparation of calibration standards and quality control samples}

The standard stock solutions of SMV, SMV-A, ATV, 2-OH-ATV, 4$\mathrm{OH}-\mathrm{ATV}, \mathrm{RSV}$ and IS were prepared separately at a concentration of $50 \mu \mathrm{g} / \mathrm{ml}$ each in methanol. Stock solutions were stored at $-20^{\circ} \mathrm{C}$ until used for the preparation of working solutions. A mixture of $10 \mu \mathrm{g} / \mathrm{ml}$ each (SMV, SMV-A, ATV, 2-OH-ATV, 4-OH-ATV, RSV) was prepared from the stock solutions by a dilution with acetonitrile. Standard working solutions were prepared by serial dilutions of the $10 \mu \mathrm{g} / \mathrm{ml}$ standard working solution mixture with acetonitrile to obtain concentrations of $0.0025,0.005,0.01,0.025,0.05,0.1,0.25$, 0.5 , and $1 \mu \mathrm{g} / \mathrm{ml}$. These standard working solutions were used to spike the plasma samples to yield the calibration standards of 0.25 , $0.5,1,2.5,5,10,25,50$, and $100 \mathrm{ng} / \mathrm{ml}$.

\subsection{Plasma sample preparation}

Liquid-liquid extraction was used for plasma samples preparation. A plasma sample $(200 \mu \mathrm{l})$ was spiked with $10 \mu \mathrm{l}$ of triglyceride mixture (as needed for lipemic group) and $20 \mu \mathrm{l}$ of IS ( $500 \mathrm{ng} / \mathrm{ml}$ in acetonitrile). Blank plasma samples were also spiked with $20 \mu \mathrm{l}$ of the required analyte concentrations to prepare the samples for calibration curve of individual analytes and the quality control samples. Ethyl acetate $(1 \mathrm{ml})$ was then added, and the mixture was vortexed for 3 min. After centrifugation with $17,968 \times g$ for $20 \mathrm{~min}$ at $4^{\circ} \mathrm{C}$, the upper phase was transferred to another vial and evaporated to dryness in a stream of air at room temperature $\left(25^{\circ} \mathrm{C}\right)$. The residue was reconstituted in $100 \mu \mathrm{l}$ of water/acetonitrile $(70: 30 \mathrm{v} / \mathrm{v})$ for LC-MS/MS analysis. 

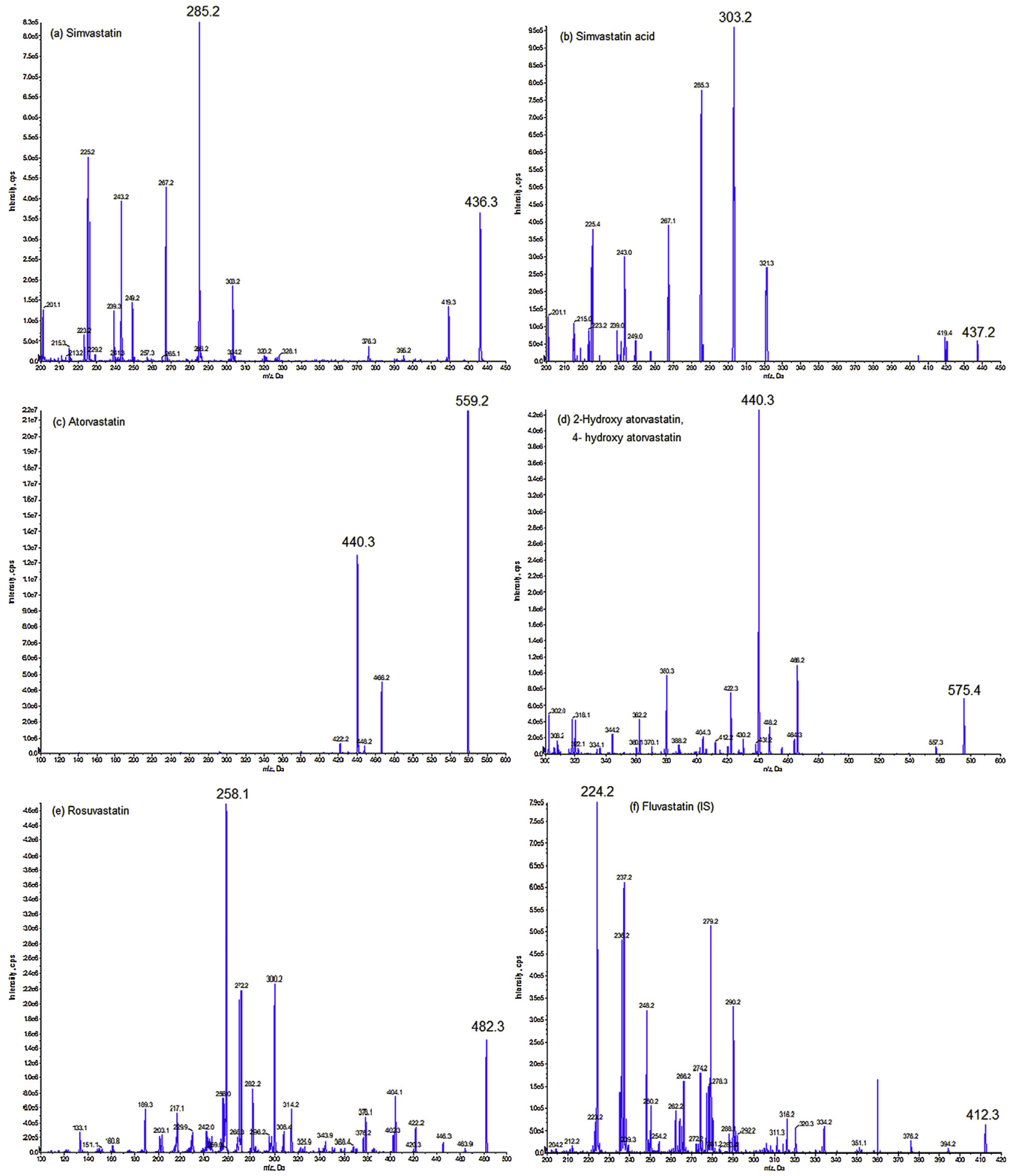

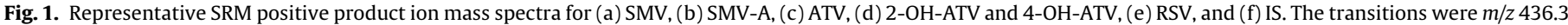

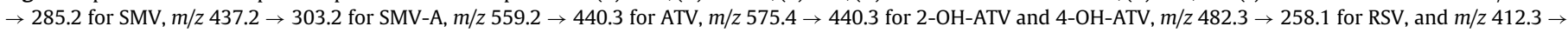
224.2 for IS.

\subsection{Method validation}

Method validation was performed according to the US FDA Guidelines of "Bioanalytical Method Validation: Guidance for Industry" [10] for (1) selectivity and specificity, (2) sensitivity and carryover, (3) linearity, (4) accuracy and precision, (5) extraction recovery (6) matrix effect, and (7) stability. Each analytical run included samples of double blank plasma (no analytes nor IS), blank (no analytes, with IS), and calibration standards. Replicate sets of quality control samples were included in the run.

\subsubsection{Selectivity and specificity}

Selectivity and specificity were evaluated by analyzing six different lots of un-pooled blank human plasma matrix samples with triglyceride levels of $52-103 \mathrm{mg} / \mathrm{dL}$. The same six lots were spiked with triglyceride mixture (to reach $352-403 \mathrm{mg} / \mathrm{dL}$ ), and 
the selectivity and specificity were assessed in the presence of high triglyceride levels. The double blank samples should not have any interference at the retention time of each analyte and the IS.

\subsubsection{Sensitivity and carryover}

Sensitivity was assessed by analyzing six replicates of spiked LLOQ samples, with accuracy and precision within $20 \%$ of the nominal concentration of the LLOQ. The LLOQ was determined as the concentration producing a peak response of at least 5:1 the response of blank plasma at the same retention time. Carryover was assessed by injecting 5 samples at the high QC concentration followed by three blank injections. Carryover acceptance criteria is less than $20 \%$ of the LLOQ response.

\subsubsection{Linearity}

Linear calibration curves were constructed by plotting the peak area ratios of each analyte/IS versus the analyte concentrations over the range of $0.25-100 \mathrm{ng} / \mathrm{ml}$. The linearity was assessed using linear regression analysis. Calibration curves were constructed in plasma with low and high triglyceride levels.

\subsubsection{Accuracy and precision}

Quality control samples, containing LLOQ, low (LQC), medium (MQC), and high (HQC) concentrations of $0.25,0.5,5$, and $80 \mathrm{ng} / \mathrm{ml}$, respectively, of each analyte were used to establish the accuracy and precision of the assay. Quality control samples used for the determination of accuracy and precision were prepared from a stock solution different from the one used to prepare the calibration curve samples. Both intra-day and inter-day accuracy and precision were evaluated by analyzing six replicates of the four different concentrations on three different days. The accuracy was expressed as a percentage of the nominal concentration, and the precision was expressed by the \% of coefficient of variation. The acceptable criteria for accuracy is $\pm 15 \%$ and the precision is $\leq 15 \%$ except at LLOQ, where the acceptable deviation is up to $20 \%$ in accuracy and precision. The accuracy and precision of the method were assessed in plasma with low and high triglyceride levels.

\subsubsection{Extraction recovery}

Recovery of the analytes and the IS from the extraction method was evaluated by comparing the peak areas of each analyte and the IS between two samples, where the plasma was spiked with the analytes mixture after and before the extraction (six each of LQC, MQC and HQC), respectively. Recovery does not need to be $100 \%$, according to FDA guidelines, but should be consistent, precise, and reproducible. Extraction recovery was performed with low and high triglyceride levels for each analyte. For the IS, extraction recovery from high triglyceride plasma was performed.

\subsubsection{Matrix effect}

Matrix effect was evaluated by comparing the peak areas of each analyte in plasma samples that were extracted before spiking the analyte with that in neat solution. Matrix effect was determined using six different sources of plasma at the three different QC concentrations. At first, matrix effect was performed with plasma from six different individuals with triglyceride levels of $52-103 \mathrm{mg} / \mathrm{dL}$. The test was repeated with plasma that was spiked with a known concentration of triglycerides to reach concentrations more than $300 \mathrm{mg} / \mathrm{dl}$ (352-403 mg/dl). Matrix effect on the IS was assessed using the plasma with high triglyceride levels.

\subsubsection{Stability}

Tests on freeze and thaw, bench-top, long-term, processed sample, and stock solution stability were performed using six replicates at each of the QC concentration levels. Freeze and thaw stability was determined after three cycles of freeze and thaw from $-80^{\circ} \mathrm{C}$ to room temperature. Bench-top stability was assessed after the QC samples were kept at room temperature for $4 \mathrm{~h}$. Long-term stability was assessed after the QC samples were kept at $-80^{\circ} \mathrm{C}$ for one month. Processed sample stability was determined by the quantification of QC samples prior to and after storage in the autosampler $\left(20^{\circ} \mathrm{C}\right)$ for $24 \mathrm{~h}$. Stock solution stability was determined by comparing the analysis results of samples freshly prepared and after storage at $-20^{\circ} \mathrm{C}$ for 1 month.

\subsection{Pharmacokinetic study}

Clinical samples were collected from obese patients (one sample/patient at each visit) before undergoing GBS (baseline), and at follow-up visits at 3, 6, and 12 months after the surgery. Twenty-six patients had been taking one of the statins at various doses, 10, 20, 40 , or $80 \mathrm{mg}$ for SMV, 10,40 , or $80 \mathrm{mg}$ for ATV, or $5,10,20$, or $40 \mathrm{mg}$ for RSV. The sample collection time was at different time points after dose for each patient. The samples were collected from obese patients as a part of another ongoing clinical study aimed to explore the impact of GBS on the pharmacokinetics and pharmacodynamics of SMV, ATV and RSV. All samples were stored at $-80^{\circ} \mathrm{C}$ until analysis. Twenty patients were not on any statin and were used as a control group for the pharmacodynamic parameters.

\subsection{Statistical analysis}

Statistical analysis was performed using SPSS $^{\circledR}$ Version 22, with significant level set at $\mathrm{p}<0.05$. Inter-day and inter-day accuracy, precision, extraction recovery, and matrix effect results were compared at each QC concentration level by Student's $t$-test between plasma containing low and high triglycerides. Demographic data of age between statin and non-statin groups was compared using Student's $t$-test.

\section{Results}

\subsection{Selectivity and specificity}

The degrees of interference by endogenous plasma constituents with all the analytes and the IS were evaluated by analyzing processed blank plasma with low and high triglyceride levels by inspecting the resulted chromatograms. No significant interference was observed in the blank plasma chromatograms (in plasma with either low or high triglyceride levels) at the retention times of SMV (3.8 min), SMV-A (3.6 min), ATV (3.2 min), 2-OH-ATV (3.1 min), 4OH-ATV (2.8 $\mathrm{min})$, RSV (2.9 min) and the IS ( $3.3 \mathrm{~min})$ as shown in Fig. 2. There was a peak from an endogenous substance at $3.6 \mathrm{~min}$ when monitoring the transition for rosuvastatin in blank plasma, but it did not interfere with the quantification of rosuvastatin which elutes at $2.9 \mathrm{~min}$.

\subsection{Sensitivity}

The LLOQ for all analytes was $0.25 \mathrm{ng} / \mathrm{ml}$ yielding a response/baseline ratio of $>5$ for each analyte compared to blank plasma. The chromatograms for all six analytes at LLOQ is represented in Fig. 2 . No carryover ( $<10 \%$ of LLOQ signal for all analytes) was observed in the blank injection following 5 injections of samples at the high QC concentration.

\subsection{Linearity}

The calibration curves were linear over the concentration range of $0.25-100 \mathrm{ng} / \mathrm{ml}$ for all the analytes in plasma with both low and high triglyceride levels. Linear regression equations with a weighting factor of $1 / x$ of the analyte to the IS concentrations produced the 


\section{Low TG Levels}
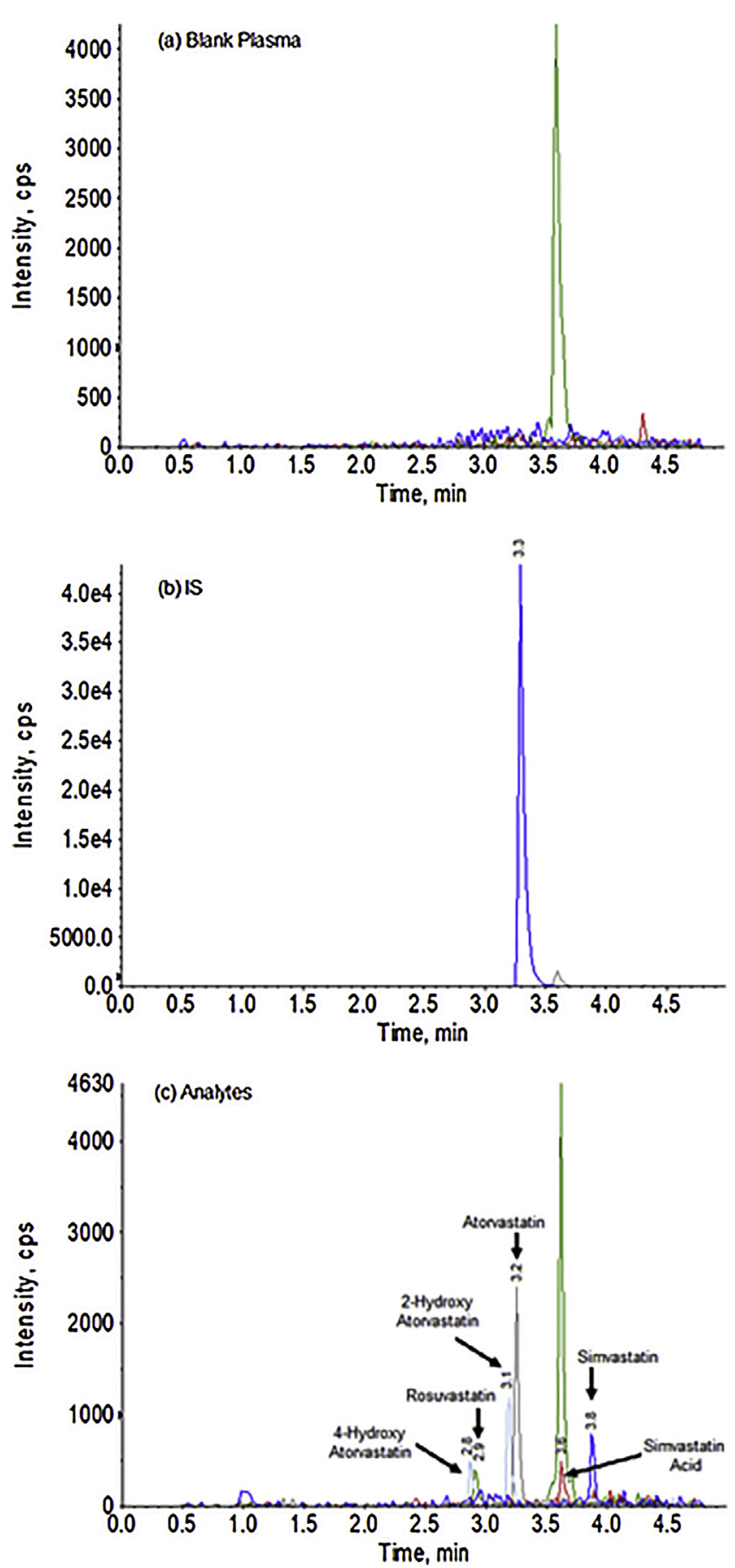

High TG Levels
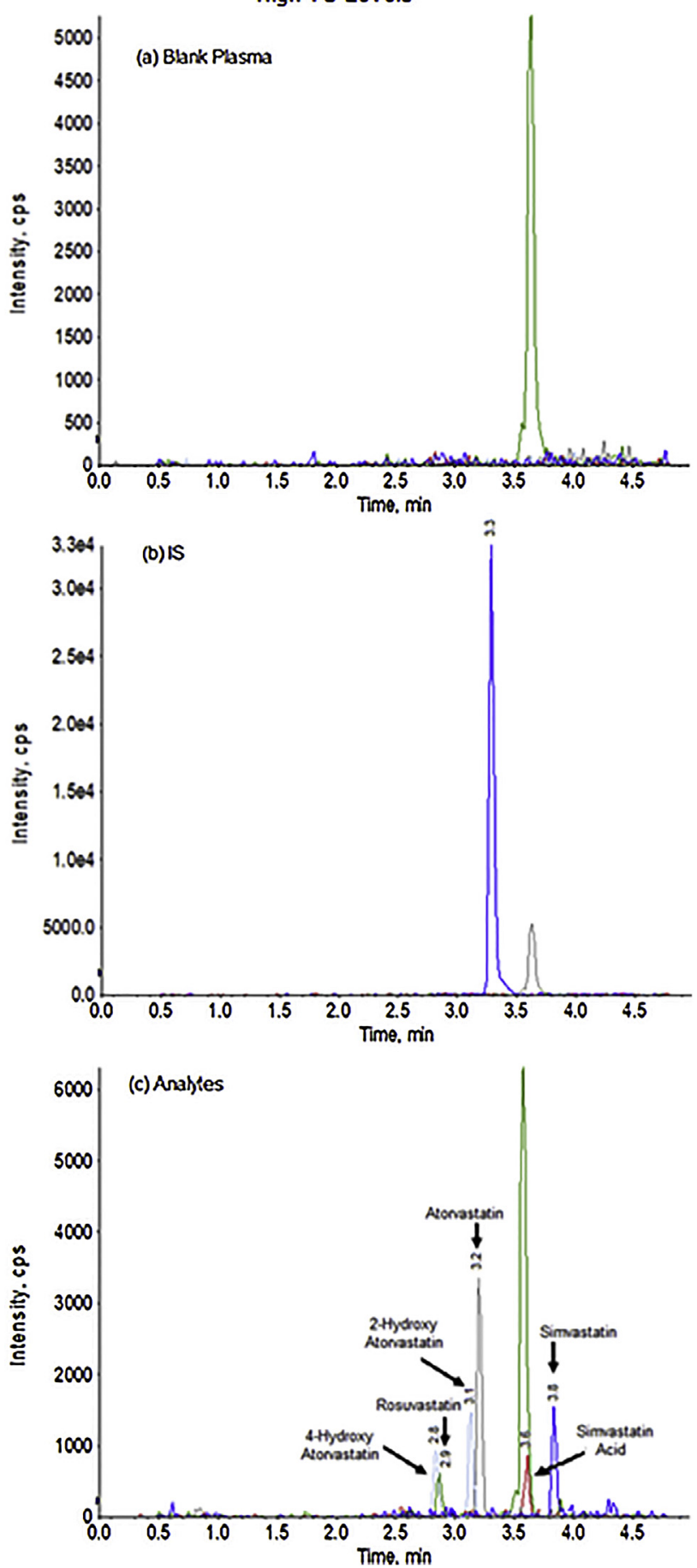

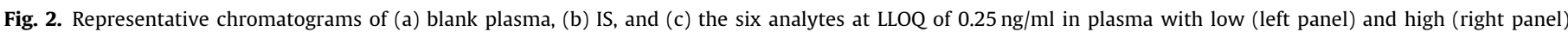
triglyceride levels. The retention times for SMV, SMV-A, ATV, 2-OH-ATV, 4-OH-ATV, RSV, and IS are 3.8, 3.6, 3.2, 3.1, 2.8, 2.9, and 3.3 min, respectively.

Table 2

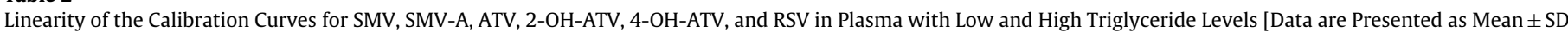
$(\% \mathrm{CV})]$.

\begin{tabular}{|c|c|c|c|c|}
\hline \multirow[b]{2}{*}{ Analyte } & \multicolumn{2}{|l|}{ Low TG Levels $(n=6)$} & \multicolumn{2}{|l|}{ High TG Levels $(\mathrm{n}=4)$} \\
\hline & Slope & $\mathrm{r}^{2}$ & Slope & $\mathrm{r}^{2}$ \\
\hline SMV & $0.045 \pm 0.004(7.94)$ & $0.987 \pm 0.009(0.92)$ & $0.051 \pm 0.002(4.07)$ & $0.990 \pm 0.008(0.75)$ \\
\hline SMV-A & $0.014 \pm 0.001$ & $0.991 \pm 0.007(0.72)$ & $0.013 \pm 0.001(7.97)$ & $0.990 \pm 0.004(0.42)$ \\
\hline ATV & $0.086 \pm 0.009(9.94)$ & $0.991 \pm 0.005(0.51)$ & $0.085 \pm 0.004(4.43)$ & $0.994 \pm 0.003(0.28)$ \\
\hline 2-OH-ATV & $0.053 \pm 0.005(8.68)$ & $0.990 \pm 0.004(0.43)$ & $0.049 \pm 0.002(3.39)$ & $0.994 \pm 0.001(0.12)$ \\
\hline 4-OH-ATV & $0.019 \pm 0.002(9.69)$ & $0.990 \pm 0.006(0.56)$ & $0.020 \pm 0.001(6.04)$ & $0.991 \pm 0.004(0.24)$ \\
\hline RSV & $0.018 \pm 0.001$ & $0.991 \pm 0.006(0.64)$ & $0.017 \pm 0.001(6.83)$ & $0.995 \pm 0.001(0.15)$ \\
\hline
\end{tabular}


Table 3

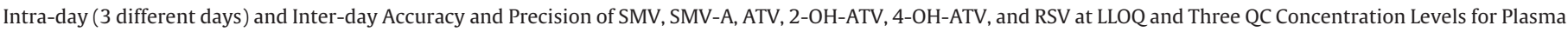
with Low Triglyceride Levels.

\begin{tabular}{|c|c|c|c|c|c|c|c|c|}
\hline \multirow{3}{*}{$\begin{array}{l}\text { Concentration } \\
(\mathrm{ng} / \mathrm{ml})\end{array}$} & \multicolumn{2}{|l|}{ Day $1(n=6)$} & \multicolumn{2}{|l|}{ Day $2(n=6)$} & \multicolumn{2}{|l|}{ Day $3(n=6)$} & \multicolumn{2}{|c|}{ Inter-day $(n=18)$} \\
\hline & Accuracy (\%) & Precision (\%) & Accuracy (\%) & Precision (\%) & Accuracy (\%) & Precision (\%) & Accuracy (\%) & Precision (\%) \\
\hline & Mean \pm SD & & Mean \pm SD & & Mean \pm SD & & Mean \pm SD & \\
\hline \multicolumn{9}{|l|}{ SMV } \\
\hline 0.25 & $101.30 \pm 7.52$ & 7.42 & $96.80 \pm 3.56$ & 3.68 & $99.70 \pm 5.40$ & 5.41 & $99.27 \pm 5.71$ & 5.75 \\
\hline 0.5 & $97.53 \pm 4.88$ & 5.00 & $103.95 \pm 5.42$ & 5.21 & $99.00 \pm 6.82$ & 6.89 & $100.16 \pm 6.11$ & 6.10 \\
\hline 5 & $104.38 \pm 7.92$ & 7.59 & $95.53 \pm 7.36$ & 7.71 & $95.72 \pm 4.88$ & 5.10 & $98.54 \pm 7.71$ & 7.82 \\
\hline 80 & $103.50 \pm 6.44$ & 6.22 & $98.07 \pm 6.09$ & 6.21 & $100.22 \pm 8.12$ & 8.10 & $100.59 \pm 6.91$ & 6.87 \\
\hline \multicolumn{9}{|l|}{ SMV-A } \\
\hline 0.25 & $97.58 \pm 8.53$ & 8.75 & $103.13 \pm 12.81$ & 12.42 & $99.32 \pm 4.64$ & 4.67 & $100.01 \pm 9.04$ & 9.04 \\
\hline 0.5 & $102.22 \pm 6.13$ & 5.99 & $94.72 \pm 5.72$ & 6.04 & $97.65 \pm 6.96$ & 7.13 & $98.19 \pm 6.71$ & 6.83 \\
\hline 5 & $101.05 \pm 8.80$ & 8.71 & $97.15 \pm 4.93$ & 5.08 & $97.98 \pm 7.33$ & 7.48 & $98.73 \pm 6.98$ & 7.07 \\
\hline 80 & $96.30 \pm 8.49$ & 8.81 & $101.70 \pm 4.85$ & 4.77 & $98.67 \pm 6.65$ & 6.74 & $98.89 \pm 6.80$ & 6.88 \\
\hline \multicolumn{9}{|l|}{ ATV } \\
\hline 0.25 & $104.02 \pm 6.69$ & 6.43 & $109.43 \pm 9.17$ & 8.38 & $103.50 \pm 6.47$ & 6.25 & $105.65 \pm 7.61$ & 7.20 \\
\hline 0.5 & $95.95 \pm 8.79$ & 9.16 & $97.48 \pm 7.07$ & 7.25 & $95.05 \pm 9.07$ & 9.54 & $96.16 \pm 7.92$ & 8.23 \\
\hline 5 & $102.63 \pm 12.43$ & 12.11 & $100.75 \pm 9.48$ & 9.41 & $98.57 \pm 8.28$ & 8.40 & $100.65 \pm 9.74$ & 9.68 \\
\hline 80 & $100.22 \pm 5.32$ & 5.31 & $97.68 \pm 7.00$ & 7.17 & $100.67 \pm 4.89$ & 4.85 & $99.52 \pm 5.62$ & 5.65 \\
\hline \multicolumn{9}{|l|}{ 2-OH-ATV } \\
\hline 0.25 & $102.93 \pm 8.41$ & 8.17 & $104.05 \pm 6.63$ & 6.37 & $101.25 \pm 6.23$ & 6.15 & $102.74 \pm 6.82$ & 6.64 \\
\hline 0.5 & $103.35 \pm 7.74$ & 7.49 & $97.95 \pm 9.41$ & 9.61 & $99.17 \pm 10.70$ & 10.79 & $100.16 \pm 9.11$ & 9.10 \\
\hline 5 & $100.27 \pm 7.63$ & 7.61 & $101.63 \pm 10.81$ & 10.63 & $98.55 \pm 10.47$ & 10.62 & $100.15 \pm 9.24$ & 9.23 \\
\hline 80 & $98.28 \pm 5.22$ & 5.31 & $99.68 \pm 5.71$ & 5.73 & $102.17 \pm 4.31$ & 4.22 & $100.04 \pm 5.08$ & 5.08 \\
\hline \multicolumn{9}{|l|}{ 4-OH-ATV } \\
\hline 0.25 & $97.18 \pm 3.55$ & 3.65 & $105.67 \pm 7.34$ & 6.95 & $104.15 \pm 9.25$ & 8.89 & $102.33 \pm 7.69$ & 7.52 \\
\hline 0.5 & $98.18 \pm 7.23$ & 7.37 & $98.58 \pm 9.09$ & 9.22 & $95.60 \pm 9.67$ & 10.12 & $97.46 \pm 8.31$ & 8.53 \\
\hline 5 & $102.52 \pm 3.76$ & 3.67 & $101.27 \pm 9.09$ & 8.97 & $98.32 \pm 8.72$ & 8.87 & $99.81 \pm 7.40$ & 7.41 \\
\hline 80 & $95.90 \pm 9.57$ & 9.98 & $95.02 \pm 7.80$ & 8.21 & $100.58 \pm 4.02$ & 4.00 & $97.17 \pm 7.48$ & 7.70 \\
\hline \multicolumn{9}{|l|}{ RSV } \\
\hline 0.25 & $99.00 \pm 12.37$ & 12.50 & $104.75 \pm 4.60$ & 4.39 & $96.20 \pm 8.37$ & 8.70 & $99.98 \pm 9.23$ & 9.24 \\
\hline 0.5 & $101.85 \pm 7.71$ & 7.57 & $100.28 \pm 10.04$ & 10.02 & $102.30 \pm 10.16$ & 9.93 & $101.48 \pm 8.85$ & 8.72 \\
\hline 5 & $98.65 \pm 10.96$ & 11.11 & $96.30 \pm 9.85$ & 10.23 & $96.58 \pm 3.23$ & 3.34 & $97.18 \pm 8.25$ & 8.49 \\
\hline 80 & $99.68 \pm 7.03$ & 7.05 & $97.03 \pm 4.96$ & 5.12 & $102.15 \pm 4.89$ & 4.79 & $99.62 \pm 5.78$ & 5.81 \\
\hline
\end{tabular}

best fit equations for the concentration-detector response relationship. The mean \pm SD coefficients of determination $\left(\mathrm{r}^{2}\right)$ and slopes of the calibration curves from inter-day batches are presented in Table 2.

\subsection{Accuracy and precision}

Accuracy and precision data for intra- and inter-day plasma samples of SMV, SMV-A, ATV, 2-OH-ATV, 4-OH-ATV, RSV are presented in Tables 3 and 4 for plasma with low and high triglyceride levels, respectively. The assay values for intra-day and inter-day accuracy and precision for plasma with either low or high triglyceride levels were within the acceptable 15\% limit. The intra-day accuracy and precision values for plasma with low triglycerides ranged from 96 to $104 \%$ and 4 to $8 \%$ for SMV, 95 to $103 \%$ and 5 to $12 \%$ for SMV-A, 95 to $109 \%$ and 5 to $12 \%$ for ATV, 98 to $104 \%$ and 4 to $11 \%$ for $2-\mathrm{OH}-\mathrm{ATV}, 95$ to $106 \%$ and 4 to $10 \%$ for $4-\mathrm{OH}-\mathrm{ATV}, 96$ to $105 \%$ and 3 to $13 \%$ for RSV. The assay values for inter-day accuracy and precision for plasma with low triglycerides ranged from 99 to $101 \%$ and 6 to $8 \%$ for SMV, 98 to $100 \%$ and 7 to $9 \%$ for SMV-A, 96 to $106 \%$ and 6 to $10 \%$ for ATV, 100 to $103 \%$ and 5 to $9 \%$ for 2-OH-ATV, 97 to $102 \%$ and 7 to $9 \%$ for $4-O H-A T V, 97$ to $101 \%$ and 6 to $9 \%$ for RSV (Table 3 ). High triglyceride levels in the plasma did not affect the inter- or intra-day accuracy and precision of the method. The values for the intra-day accuracy and precision for plasma with high triglycerides ranged from 94 to $104 \%$ and 4 to $13 \%$ for SMV, 93 to $103 \%$ and 4 to $11 \%$ for SMV-A, 87 to $104 \%$ and 3 to $13 \%$ for ATV, 90 to $114 \%$ and 5 to $11 \%$ for $2-\mathrm{OH}-\mathrm{ATV}, 89$ to $100 \%$ and 5 to $12 \%$ for 4-OH-ATV, 93 to $102 \%$ and 6 to $14 \%$ for RSV. The assay values for inter-day accuracy and precision for plasma with high triglycerides ranged from 98 to $99 \%$ and 6 to $10 \%$ for SMV, 95 to $100 \%$ and 7 to $10 \%$ for SMV-A, 98 to $99 \%$ and 8 to $11 \%$ for ATV, 96 to $103 \%$ and 8 to
12\% for 2 -OH-ATV, 93 to $98 \%$ and 6 to $10 \%$ for 4 -OH-ATV, 94 to $99 \%$ and 7 to $11 \%$ for RSV (Table 4 ).

\subsection{Extraction recovery}

The mean $( \pm S D)$ extraction recovery are presented in Table 5. The recovery of the analytes from plasma samples with low triglyceride levels was between $98-100 \%$ for SMV, $88-96 \%$ for SMV-A, 97-100\% for ATV, 92-98 for 2-OH-ATV, 97-99\% for 4-OH-ATV, and 88-95 for RSV. The recovery of the analytes from plasma samples with high triglyceride levels were comparable to those from plasma with low triglyceride levels, 95-97\% for SMV, 91-98\% for SMV-A, 93-97\% for ATV, 95-97 for 2-OH-ATV, 95-97\% for 4-OH-ATV, and 94-98 for RSV. The extraction recovery was reproducible at the three QC concentration levels. The extraction recovery for the internal standard was $88.12 \pm 7.84 \%$ from plasma with high triglyceride levels. Since the extraction recovery of the IS from high TG plasma was above $85 \%$, we did not test for the extraction recovery using low TG plasma.

\subsection{Matrix effect}

No significant matrix effect was observed in plasma samples with low triglyceride concentrations. Matrix effect was negligible (within $\pm 10 \%$ ) at the three QC concentration levels, with a range of $93-110 \%$. When plasma spiked with triglycerides to reach levels higher than $300 \mathrm{mg} / \mathrm{dl}$ (352-403 mg/dl) was used in the matrix effect test, the matrix effect ranged $92-103 \%$, similar to those with plasma of low triglyceride levels (Table 6). The assay value for matrix effect on the IS was $93.51 \pm 6.67$ for plasma with high triglyceride levels. Matrix effect was negligible for the IS in plasma with high TG levels, so the test was not repeated in plasma with low TG levels. 
Table 4

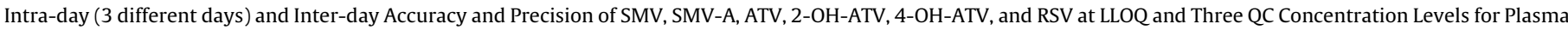
with High Triglyceride Levels.

\begin{tabular}{|c|c|c|c|c|c|c|c|c|}
\hline \multirow{3}{*}{$\begin{array}{l}\text { Concentration } \\
(\mathrm{ng} / \mathrm{ml})\end{array}$} & \multicolumn{2}{|l|}{ Day $1(n=6)$} & \multicolumn{2}{|l|}{ Day $2(n=6)$} & \multicolumn{2}{|l|}{ Day $3(n=6)$} & \multicolumn{2}{|c|}{ Inter-day $(\mathrm{n}=18)$} \\
\hline & Accuracy (\%) & Precision (\%) & Accuracy (\%) & Precision (\%) & Accuracy (\%) & Precision (\%) & Accuracy (\%) & Precision (\%) \\
\hline & Mean \pm SD & & Mean \pm SD & & Mean \pm SD & & Mean \pm SD & \\
\hline \multicolumn{9}{|l|}{ SMV } \\
\hline 0.25 & $98.53 \pm 8.73$ & 8.86 & $98.00 \pm 7.10$ & 7.25 & $97.61 \pm 8.72$ & 8.93 & $98.05 \pm 7.73$ & 7.88 \\
\hline 0.5 & $101.20 \pm 12.69$ & 12.54 & $95.20 \pm 6.08$ & 6.39 & $96.23 \pm 10.69$ & 11.11 & $97.54 \pm 9.96$ & 10.21 \\
\hline 5 & $97.67 \pm 5.16$ & 5.28 & $93.63 \pm 7.90$ & 8.44 & $104.28 \pm 3.90$ & 3.74 & $98.53 \pm 7.14$ & 7.25 \\
\hline 80 & $99.79 \pm 7.56$ & 7.57 & $95.02 \pm 5.04$ & 5.30 & $98.70 \pm 5.60$ & 5.68 & $97.84 \pm 6.16$ & 6.29 \\
\hline \multicolumn{9}{|l|}{ SMV-A } \\
\hline 0.25 & $102.33 \pm 8.73$ & 8.53 & $101.00 \pm 6.48$ & 6.42 & $98.08 \pm 7.84$ & 7.99 & $100.47 \pm 7.50$ & 7.46 \\
\hline 0.5 & $100.80 \pm 10.15$ & 10.07 & $95.07 \pm 8.43$ & 8.86 & $102.50 \pm 11.55$ & 11.27 & $99.46 \pm 10.06$ & 10.11 \\
\hline 5 & $96.20 \pm 7.67$ & 7.98 & $99.32 \pm 7.91$ & 7.97 & $93.68 \pm 7.75$ & 8.28 & $96.40 \pm 7.68$ & 7.97 \\
\hline 80 & $96.47 \pm 7.77$ & 8.06 & $93.37 \pm 3.45$ & 3.69 & $96.28 \pm 8.16$ & 8.47 & $95.37 \pm 6.55$ & 6.87 \\
\hline \multicolumn{9}{|l|}{ ATV } \\
\hline 0.25 & $101.64 \pm 3.03$ & 2.98 & $87.42 \pm 4.70$ & 5.37 & $104.04 \pm 12.75$ & 12.25 & $97.70 \pm 10.68$ & 10.93 \\
\hline 0.5 & $95.87 \pm 8.17$ & 8.52 & $100.30 \pm 12.96$ & 12.92 & $100.17 \pm 9.75$ & 9.73 & $98.78 \pm 10.07$ & 10.20 \\
\hline 5 & $101.97 \pm 9.05$ & 8.87 & $101.49 \pm 9.03$ & 8.90 & $93.70 \pm 8.25$ & 8.80 & $99.05 \pm 9.13$ & 9.21 \\
\hline 80 & $95.52 \pm 7.75$ & 8.11 & $99.18 \pm 8.75$ & 8.82 & $101.82 \pm 6.10$ & 5.99 & $98.84 \pm 7.63$ & 7.72 \\
\hline \multicolumn{9}{|l|}{ 2-OH-ATV } \\
\hline 0.25 & $100.83 \pm 6.94$ & 6.88 & $111.00 \pm 6.72$ & 6.06 & $89.93 \pm 6.08$ & 6.77 & $100.59 \pm 10.80$ & 10.74 \\
\hline 0.5 & $90.72 \pm 9.71$ & 10.71 & $103.37 \pm 8.28$ & 8.01 & $113.67 \pm 7.03$ & 6.19 & $102.86 \pm 12.82$ & 12.47 \\
\hline 5 & $97.70 \pm 5.01$ & 5.13 & $100.76 \pm 9.00$ & 8.94 & $93.32 \pm 10.21$ & 10.94 & $97.26 \pm 8.47$ & 8.71 \\
\hline 80 & $93.85 \pm 7.75$ & 8.26 & $93.42 \pm 6.53$ & 6.99 & $100.18 \pm 6.34$ & 6.33 & $95.82 \pm 7.22$ & 7.54 \\
\hline \multicolumn{9}{|l|}{ 4-OH-ATV } \\
\hline 0.25 & $98.00 \pm 7.21$ & 7.36 & $88.67 \pm 10.66$ & 12.02 & $92.71 \pm 8.20$ & 8.84 & $93.12 \pm 9.16$ & 9.84 \\
\hline 0.5 & $94.15 \pm 8.15$ & 8.65 & $98.48 \pm 5.52$ & 5.61 & $99.12 \pm 7.51$ & 7.58 & $97.25 \pm 7.09$ & 7.29 \\
\hline 5 & $98.48 \pm 5.20$ & 5.28 & $91.83 \pm 5.82$ & 6.34 & $97.20 \pm 5.55$ & 5.71 & $95.84 \pm 5.98$ & 6.24 \\
\hline 80 & $97.08 \pm 8.65$ & 8.91 & $98.00 \pm 7.46$ & 7.61 & $100.26 \pm 10.24$ & 10.21 & $98.45 \pm 8.43$ & 8.56 \\
\hline \multicolumn{9}{|l|}{ RSV } \\
\hline 0.25 & $96.88 \pm 9.88$ & 10.19 & $98.20 \pm 13.62$ & 13.87 & $100.42 \pm 11.60$ & 11.55 & $98.50 \pm 11.18$ & 11.35 \\
\hline 0.5 & $93.25 \pm 8.91$ & 9.56 & $92.72 \pm 11.01$ & 11.87 & $97.00 \pm 10.66$ & 10.99 & $94.32 \pm 9.81$ & 10.40 \\
\hline 5 & $101.67 \pm 6.39$ & 6.29 & $98.55 \pm 7.53$ & 7.64 & $95.77 \pm 7.43$ & 7.76 & $98.66 \pm 7.15$ & 7.25 \\
\hline 80 & $96.33 \pm 7.23$ & 7.50 & $95.45 \pm 8.96$ & 9.39 & $100.38 \pm 7.41$ & 7.39 & $97.39 \pm 7.75$ & 7.96 \\
\hline
\end{tabular}

Table 5

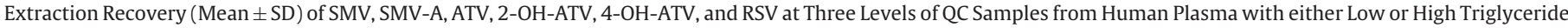
levels Using Liquid-liquid Extraction Method.

\begin{tabular}{|c|c|c|c|c|c|c|}
\hline \multirow[b]{2}{*}{ Concentration (ng/ml), $\mathrm{n}=6$} & \multicolumn{3}{|l|}{ Low TG Levels } & \multicolumn{3}{|l|}{ High TG Levels } \\
\hline & 0.5 & 5 & 80 & 0.5 & 5 & 80 \\
\hline SMV & $99.69 \pm 5.28$ & $98.37 \pm 4.42$ & $99.82 \pm 7.31$ & $95.21 \pm 10.05$ & $97.26 \pm 8.83$ & $97.40 \pm 6.80$ \\
\hline SMV-A & $88.49 \pm 6.48$ & $96.04 \pm 6.01$ & $94.32 \pm 4.80$ & $91.29 \pm 3.21$ & $96.46 \pm 3.80$ & $97.75 \pm 5.89$ \\
\hline ATV & $98.84 \pm 6.77$ & $96.94 \pm 7.86$ & $100.37 \pm 8.18$ & $93.06 \pm 8.21$ & $96.41 \pm 4.99$ & $97.36 \pm 3.03$ \\
\hline 2-OH-ATV & $92.15 \pm 6.20$ & $97.71 \pm 4.52$ & $96.31 \pm 4.17$ & $94.93 \pm 12.20$ & $95.29 \pm 2.52$ & $96.97 \pm 5.03$ \\
\hline 4-OH-ATV & $99.17 \pm 6.33$ & $97.97 \pm 8.92$ & $96.97 \pm 9.60$ & $94.86 \pm 12.82$ & $96.67 \pm 9.51$ & $96.47 \pm 8.75$ \\
\hline RSV & $87.99 \pm 6.28$ & $94.62 \pm 6.67$ & $95.36 \pm 4.75$ & $97.77 \pm 10.42$ & $94.18 \pm 4.41$ & $95.28 \pm 10.02$ \\
\hline
\end{tabular}

Table 6

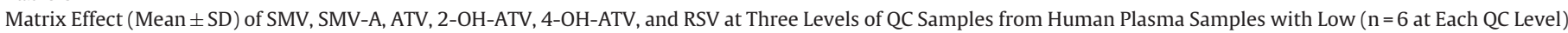
and High ( $\mathrm{n}=6$ at Each QC Level) Triglyceride Levels.

\begin{tabular}{|c|c|c|c|c|c|c|}
\hline Concentration (ng/ml) & SMV & SMV-A & ATV & 2-OH-ATV & 4-OH-ATV & RSV \\
\hline \multicolumn{7}{|l|}{ Low TG Levels } \\
\hline 0.5 & $97.76 \pm 4.14$ & $92.63 \pm 7.41$ & $110.42 \pm 6.39$ & $102.93 \pm 8.35$ & $101.84 \pm 9.10$ & $93.53 \pm 2.64$ \\
\hline 5 & $96.61 \pm 9.08$ & $99.98 \pm 8.29$ & $102.78 \pm 10.23$ & $96.50 \pm 11.48$ & $96.06 \pm 5.96$ & $94.64 \pm 10.12$ \\
\hline 80 & $96.23 \pm 5.93$ & $103.01 \pm 8.48$ & $97.45 \pm 4.40$ & $99.08 \pm 7.15$ & $97.84 \pm 10.47$ & $93.83 \pm 9.04$ \\
\hline \multicolumn{7}{|l|}{ High TG Levels } \\
\hline 0.5 & $99.05 \pm 6.04$ & $97.01 \pm 7.53$ & $102.76 \pm 9.19$ & $103.23 \pm 13.68$ & $100.68 \pm 8.20$ & $98.02 \pm 8.65$ \\
\hline 5 & $93.62 \pm 5.94$ & $97.85 \pm 6.75$ & $97.05 \pm 7.98$ & $91.59 \pm 6.08$ & $102.52 \pm 5.56$ & $98.20 \pm 5.71$ \\
\hline 80 & $97.02 \pm 7.49$ & $101.12 \pm 7.99$ & $94.17 \pm 7.42$ & $101.62 \pm 5.74$ & $97.97 \pm 7.99$ & $97.72 \pm 7.40$ \\
\hline
\end{tabular}

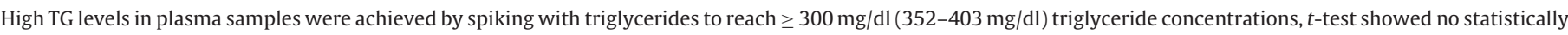
significant difference between the matrix effect at all concentration levels between plasma with low and high TG levels.

\subsection{Stability}

The conditions under which the stability experiments were performed reflect the expected conditions during sample preparation, storage, and analysis. Table 7 presents the results of the stability experiments performed under different conditions. Results of freeze and thaw stability test showed that all analytes were sta- ble (92-99\%) for three cycles when stored at $-80^{\circ} \mathrm{C}$ and thawed at room temperature. Bench-top stability test showed that the samples were stable (90-100\%) for $4 \mathrm{~h}$ at room temperature (the time required for sample preparation). Long-term stability test results showed that the analytes were adequately stable (92-98\%) for up to 1 month in plasma when stored at $-80^{\circ} \mathrm{C}$. Processed samples can be analyzed overnight $(24 \mathrm{~h})$ in the autosampler at $20^{\circ} \mathrm{C}$ without any 
Table 7

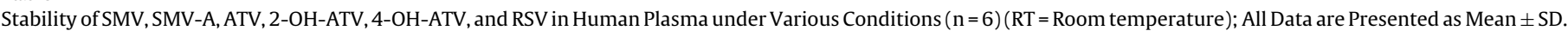

\begin{tabular}{|c|c|c|c|c|c|}
\hline \multirow[b]{2}{*}{ Concentration (ng/ml) } & \multicolumn{5}{|l|}{$\%$ of Initial Concentration } \\
\hline & $\begin{array}{l}\text { Freeze and Thaw, three } \\
\text { cycles, }-80^{\circ} \mathrm{C} \text { to RT }\end{array}$ & Bench-top, RT for $4 \mathrm{~h}$ & $\begin{array}{l}\text { Long-term, }-80^{\circ} \mathrm{C} \\
\text { for } 1 \text { month }\end{array}$ & $\begin{array}{l}\text { Processed sample, } \\
\text { autosampler, } 20^{\circ} \mathrm{C} \text { for } 24 \mathrm{~h}\end{array}$ & $\begin{array}{l}\text { Stock solution, } \\
-20^{\circ} \mathrm{C} \text { for } 1 \text { month }\end{array}$ \\
\hline \multicolumn{6}{|l|}{ SMV } \\
\hline 0.5 & $96.92 \pm 8.88$ & $96.75 \pm 6.12$ & $95.62 \pm 3.86$ & $92.30 \pm 3.22$ & $99.98 \pm 2.82$ \\
\hline 5 & $94.83 \pm 6.84$ & $97.05 \pm 8.45$ & $94.48 \pm 10.69$ & $94.46 \pm 3.00$ & $94.59 \pm 3.18$ \\
\hline 80 & $91.58 \pm 5.77$ & $99.23 \pm 8.51$ & $96.32 \pm 5.07$ & $99.74 \pm 2.43$ & $94.50 \pm 4.71$ \\
\hline \multicolumn{6}{|l|}{ SMV-A } \\
\hline 0.5 & $97.22 \pm 5.62$ & $98.97 \pm 3.50$ & $92.75 \pm 5.46$ & $98.68 \pm 3.67$ & $95.53 \pm 5.36$ \\
\hline 5 & $98.83 \pm 7.36$ & $99.82 \pm 6.69$ & $98.45 \pm 3.37$ & $95.39 \pm 7.87$ & $94.69 \pm 5.79$ \\
\hline 80 & $98.74 \pm 2.33$ & $92.42 \pm 5.75$ & $94.55 \pm 7.77$ & $94.77 \pm 5.40$ & $94.61 \pm 5.06$ \\
\hline \multicolumn{6}{|l|}{ ATV } \\
\hline 0.5 & $94.43 \pm 3.92$ & $90.35 \pm 2.28$ & $91.67 \pm 5.12$ & $93.21 \pm 6.02$ & $95.17 \pm 7.43$ \\
\hline 5 & $95.67 \pm 7.45$ & $93.27 \pm 3.81$ & $98.05 \pm 5.95$ & $94.87 \pm 4.40$ & $95.58 \pm 5.97$ \\
\hline 80 & $96.82 \pm 3.14$ & $91.67 \pm 1.77$ & $96.88 \pm 8.50$ & $91.97 \pm 3.53$ & $98.68 \pm 11.38$ \\
\hline \multicolumn{6}{|l|}{ 2-OH-ATV } \\
\hline 0.5 & $98.38 \pm 4.74$ & $96.75 \pm 6.20$ & $98.00 \pm 8.84$ & $98.12 \pm 2.49$ & $96.82 \pm 5.66$ \\
\hline 5 & $93.83 \pm 8.69$ & $98.27 \pm 10.90$ & $92.63 \pm 5.67$ & $96.70 \pm 6.84$ & $94.95 \pm 8.75$ \\
\hline 80 & $96.28 \pm 4.03$ & $94.10 \pm 6.69$ & $94.05 \pm 3.22$ & $97.00 \pm 6.12$ & $97.15 \pm 7.02$ \\
\hline \multicolumn{6}{|l|}{ 4-OH-ATV } \\
\hline 0.5 & $93.55 \pm 3.63$ & $93.63 \pm 8.91$ & $92.95 \pm 5.36$ & $94.62 \pm 9.28$ & $99.78 \pm 9.96$ \\
\hline 5 & $96.55 \pm 9.10$ & $96.83 \pm 11.15$ & $95.35 \pm 6.25$ & $98.13 \pm 7.10$ & $98.28 \pm 8.96$ \\
\hline 80 & $98.12 \pm 9.21$ & $97.02 \pm 7.95$ & $96.33 \pm 7.23$ & $97.10 \pm 5.75$ & $94.45 \pm 4.42$ \\
\hline \multicolumn{6}{|l|}{ RSV } \\
\hline 0.5 & $98.8 \pm 9.08$ & $92.85 \pm 5.44$ & $93.78 \pm 5.34$ & $97.12 \pm 4.27$ & $94.87 \pm 6.93$ \\
\hline 5 & $96.52 \pm 10.42$ & $97.60 \pm 9.34$ & $97.82 \pm 5.47$ & $96.30 \pm 9.38$ & $95.28 \pm 6.30$ \\
\hline 80 & $98.65 \pm 6.56$ & $92.83 \pm 5.08$ & $96.47 \pm 7.58$ & $97.42 \pm 8.45$ & $97.28 \pm 5.66$ \\
\hline
\end{tabular}

Table 8

Demographic Data of Patients in the Clinical Study.

\begin{tabular}{llll}
\hline & & $\begin{array}{l}\text { Statin Group } \\
(\mathrm{n}=26)\end{array}$ & $\begin{array}{l}\text { Non-Statin } \\
\text { Group }(\mathrm{n}=20)\end{array}$ \\
\hline & Mean age (yr) & $54.4 \pm 9.1^{\mathrm{a}}$ & $43.8 \pm 11.7$ \\
Racial Breakdown & Caucasian & $65.4(17)$ & $45.0(9)$ \\
$\%(\mathrm{n})$ & African American & $19.2(5)$ & $25.0(5)$ \\
& Hispanic & $7.7(2)$ & $10.0(2)$ \\
Gender \% & Other & $7.7(2)$ & $20.0(4)$ \\
(n) & Male & $42.3(11)^{\mathrm{b}}$ & $10.0(2)$ \\
\hline
\end{tabular}

a Mean age was significantly older in statin group than in non-statin group.

b Statin group has a higher \% of male patients compared to the non-statin group.

concern about the stability of all analytes (92-100\%). Lastly, stock solutions of the analytes $(50 \mu \mathrm{g} / \mathrm{ml}$, each) were stable (94-100\%) up to one month when stored at $-20^{\circ} \mathrm{C}$.

\subsection{Application}

The demographic data of patients is presented in Table 8. Patients on statins had a mean age significantly older than that of patients not on statins. In addition, statin group has a higher percentage of males and lower percentage of females compared to the non-statin group. The developed LC-MS/MS method was successfully employed for the quantifications of SMV, ATV, RSV, and their active metabolites in clinical plasma samples collected from the obese patients prior to and post-GBS. The concentrations of all three statins and their active metabolites $(\mathrm{ng} / \mathrm{ml})$ were converted to the molar concentration $(\mathrm{nM})$, then were normalized by dose/body weight $[(\mathrm{nM}) /(\mathrm{mg} / \mathrm{kg})]$. The plasma concentrations for SMV, SMV-A, ATV, 2-OH-ATV, 4-OH-ATV, and RSV from three obese patients pre- and post-surgery are presented in Fig. 3. These data were collected as a part of another ongoing clinical study.

\section{Discussion}

Statins are considered the first line treatment of hyperlipidemia, especially for their effect in reducing the risk of atherosclerotic cardiovascular diseases. Accurate quantification of medications in plasma samples is crucial for the performance of meaningful pharmacokinetics studies. Matrix effect is one of the biggest challenges in the development of any LC-MS/MS analytical method that involves a biological matrix as the sample matrix. The challenge of matrix effect is even greater if the sample source has higher levels of triglycerides, cholesterol, and other lipids than normal values, and the levels of lipids may change during the course of treatment, such as GBS. High lipid contents in the plasma not only cause concerns about matrix effect, but also specificity and recovery.

There are many publications on the analysis of a single statin and its active metabolite or metabolites. LC-MS/MS assay methods were reported for the simultaneous analysis of simvastatin and simvastatin acid [11-16], but some of these methods had a relatively long run time $(10,8$ and $6.4 \mathrm{~min}[11,13,15])$ with larger volume of plasma used $(475,300,1000,300 \mu l[11-13,16])$, compared to our developed method ( 5 min run with $200 \mu$ l of plasma). Finally, most of these method used solid-phase extraction technique for plasma sample preparation [13,12-16], which is labor intensive, more time consuming and costly than the liquid-liquid extraction method we used. Analysis methods for the quantification of ATV and its two active metabolites, 2-OH-ATV and 4-OH-ATV, have been reported [17-20]. Most of these methods use solid-phase extraction method $[17,18,20]$ or high plasma volume for the analysis (500, 1000, $1000 \mu \mathrm{l}$ [17-19]). The LLOQ of most of these methods for the determination of either SMV (ranged $0.05-2.5 \mathrm{ng} / \mathrm{ml}$ ) and its metabolite (ranged $0.05-5 \mathrm{ng} / \mathrm{ml}$ ) or ATV (ranged $0.05-0.2 \mathrm{ng} / \mathrm{ml}$ ) and its two metabolites (ranged 0.05-0.5 and $0.05-0.2 \mathrm{ng} / \mathrm{ml}$ for 2-OH-ATV and 4-OH-ATV, respectively) was lower than the LLOQ of our developed method $(0.25 \mathrm{ng} / \mathrm{ml})$. However, our method has the advantage of quantifying three statins simultaneously with their active metabolites. In addition, none of the published methods tested for the matrix effect or validate the method using plasma with high triglyceride levels (lipemic plasma). There is only one publication on the simultaneous quantification of multiple statins along with their active metabolites i.e. simvastatin, atorvastatin, lovastatin, and their active metabolites [21], but the method has a relatively long run time of $12 \mathrm{~min}$, as compared to $5 \mathrm{~min}$ of our developed method. In addition, the 


\section{Pt 44}

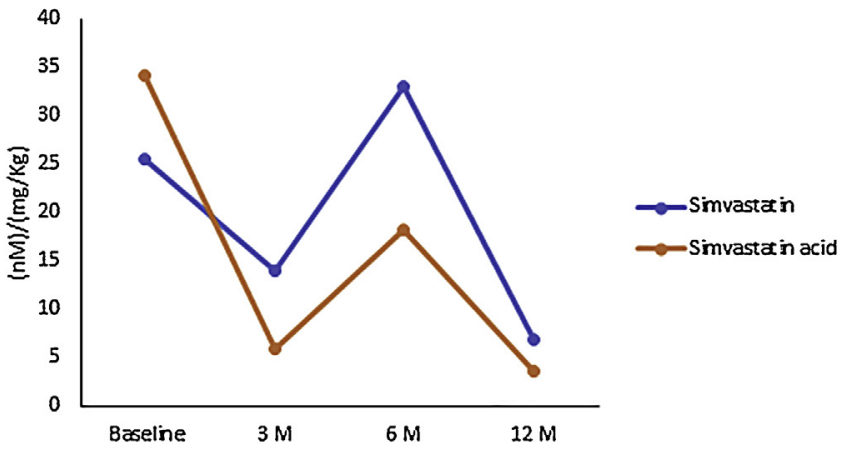

Pt 29

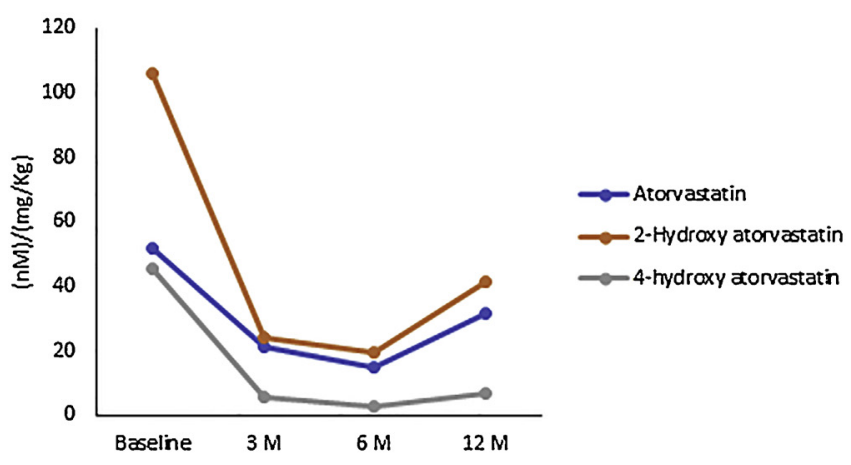

Pt 46

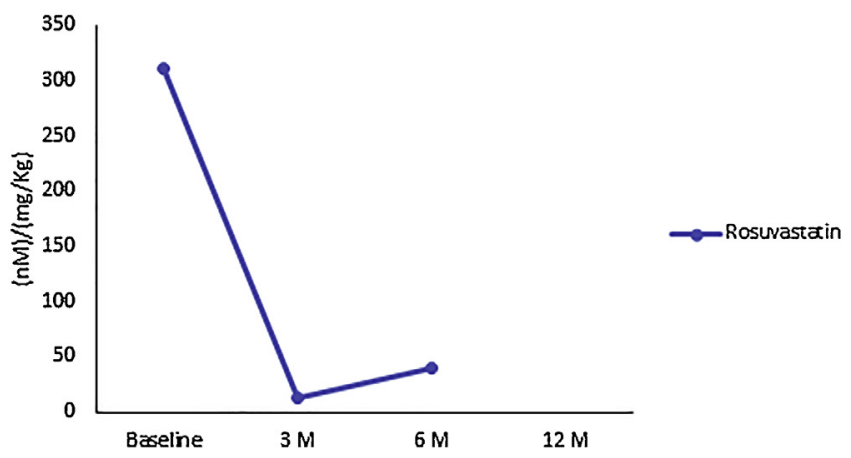

Fig. 3. Plasma concentration profiles from obese patients for (a) simvastatin and simvastatin acid, (b) atorvastatin, 2-hydroxy atorvastatin, and 4-hydroxy atorvastatin, and (c) rosuvastatin pre- and post-surgery at baseline, $3 \mathrm{M}, 6 \mathrm{M}$ and $12 \mathrm{M}$ post GBS. Molar concentrations were normalized by dose/body weight $[(\mathrm{nM}) /(\mathrm{mg} / \mathrm{kg})$. *Pt: patient ID number; $3 \mathrm{M}, 6 \mathrm{M}$ and $12 \mathrm{M}$ : 3, 6, and 12 months follow-up visit after GBS.

validation of this method did not test for the matrix effect in hyperlipidemic plasma, which is common in obese patients. Elevated levels of triglycerides and cholesterol are common in obese patients, and it renders the validation with plasma of high triglyceride levels crucial.

To our knowledge, this is the first report for the simultaneous quantification of SMV, ATV, and RSV, along with their active metabolites. The developed LC-MS/MS method in this study is sensitive, specific, accurate, precise, and reliable in the quantification of three of the most commonly prescribed statins and their active metabolites. The method is proven to be reliable in quantifying SMV, ATV, RSV and their active metabolites in hyperlipidemic plasma which is usually encountered in obese patients. This is especially useful in performing studies that require the analysis of plasma samples from obese patients who administered various statins, or when lipid levels are expected to change during the time period of the study. The linear range of this method for all the three statins and their metabolites is 0.25 (LLOQ) $-100 \mathrm{ng} / \mathrm{ml}$. Sample preparation and the extraction method (liquid-liquid extraction using ethyl acetate) were simple and efficient. Extraction recovery was higher than $88 \%$ for the three statins and their metabolites at the three quality control concentration levels from plasma with low and high triglyceride levels. No significant matrix effect for plasma samples from obese patients was observed even when the samples were spiked with extra triglycerides to reach triglyceride levels of more than $300 \mathrm{mg} / \mathrm{dl}$ (ranged 352-403 mg/dl). The pharmacokinetic application of this method enables the quantification of SMV, SMV-A, ATV, 2-OH-ATV, 4-OH-ATV, and RSV concentrations in clinical plasma samples, even if they have high levels of triglycerides. The method was successfully used in another ongoing clinical study of the three statins and their active metabolites before and after gastric bypass surgery.

\section{Conclusion}

A sensitive, specific, accurate, and reliable method was developed and validated for the simultaneous quantification of simvastatin, simvastatin acid, atorvastatin, 2-hydroxy atorvastatin, 4-hydroxy atorvastatin, and rosuvastatin in human plasma samples. This is the first report of simultaneous quantification of simvastatin, atorvastatin, and rosuvastatin with their active metabolites. The method has been validated for plasma with low $(<300 \mathrm{mg} / \mathrm{dl})$ and high $(>300 \mathrm{mg} / \mathrm{dl})$ triglyceride levels and showed no interference from the triglycerides with the quantification of all three statins and their active metabolites. The developed method was successfully used to perform a clinical pharmacokinetic study of each statin in obese patients who underwent GBS.

\section{Funding}

This work was supported by the National Institute on Minority Health and Health Disparities (NIMHD) [grant number U54MD008149].

\section{References}

[1] Y. Shitara, Y. Sugiyama, Pharmacokinetic and pharmacodynamic alterations of 3-hydroxy-3-methylglutaryl coenzyme A (HMG-CoA) reductase inhibitors: drug-drug interactions and interindividual differences in transporter and metabolic enzyme functions, Pharmacol. Ther. 112 (1) (2006) 71-105.

[2] N.J. Stone, et al., 2013 ACC/AHA guideline on the treatment of blood cholesterol to reduce atherosclerotic cardiovascular risk in adults: a report of the American College of Cardiology/American Heart Association Task Force on Practice Guidelines, Circulation 129 (25 Suppl 2) (2014) S1-45.

[3] K.R. Feingold, C. Grunfeld, et al., Obesity and dyslipidemia, in: L.J. De Groot (Ed.), Endotext, 2000, South Dartmouth (MA).

[4] N. Rifai, J.R. Merrill, R.G. Holly, Postprandial effect of a high fat meal on plasma lipid, lipoprotein cholesterol and apolipoprotein measurements, Ann. Clin. Biochem. 27 (Pt. 5) (1990) 489-493.

[5] O.A. Ismaiel, et al., Investigation of endogenous blood plasma phospholipids, cholesterol and glycerides that contribute to matrix effects in bioanalysis by liquid chromatography/mass spectrometry, J. Chromatogr. B: Analyt. Technol. Biomed. Life Sci. 878 (31) (2010) 3303-3316.

[6] L. Mayrand-Provencher, et al., Choosing the appropriate matrix to perform a scientifically meaningful lipemic plasma test in bioanalytical method validation, Bioanalysis 6 (12) (2014) 1639-1646.

[7] EMA, Guideline on Bioanalytical Method Validation, 2011, London.

[8] ANVISA, Dispõe sobre os req-uisitos mínimos para a validaç ão de métodos bioanalíticos empregados emestudos com fins de registro e pós-registro de medicamentos, Agência Nacional de Vigilancia Sanitária (Provides for the minimum requirements for the validation of bioanalytical methods used in studies for registration and post-registration of medicines), RDC 27 National Agency for Sanitary Surveillance, 2012.

[9] Q. Gu, et al., Prescription cholesterol-lowering medication use in adults aged 40 and over: United States, 2003-2012, NCHS Data Brief 177 (2014) 1-8.

[10] FDA, Bioanalytical Method Validation: Guidance for Industry, U.S. Department of Health and Human Services, 2018. 
[11] T.A. Ahmed, et al., Validated LC-MS/MS method for simultaneous determination of SIM and its acid form in human plasma and cell lysate: pharmacokinetic application, J. Pharm. Anal. 2 (6) (2012) 403-411.

[12] C. Apostolou, et al., An improved and fully validated LC-MS/MS method for the simultaneous quantification of simvastatin and simvastatin acid in human plasma, J. Pharm. Biomed. Anal. 46 (4) (2008) 771-779.

[13] B. Barrett, et al., Validated HPLC-MS/MS method for simultaneous determination of simvastatin and simvastatin hydroxy acid in human plasma, J. Pharm. Biomed. Anal. 41 (2) (2006) 517-526.

[14] M. Jemal, Z. Ouyang, M.L. Powell, Direct-injection LC-MS-MS method for high-throughput simultaneous quantitation of simvastatin and simvastatin acid in human plasma, J. Pharm. Biomed. Anal. 23 (2-3) (2000) 323-340.

[15] P. Partani, S.M. Verma, T. Monif, Development and validation of an LC-MS-MS method for determination of simvastatin and simvastatin acid in human plasma: application to a pharmacokinetic study, J. Chromatogr. Sci. 54 (8) (2016) 1385-1396.

[16] A.Y. Yang, et al., Application of a novel ultra-low elution volume 96-well solid-phase extraction method to the LC/MS/MS determination of simvastatin and simvastatin acid in human plasma, J. Pharm. Biomed. Anal. 38 (3) (2005) 521-527.
[17] C. Ghosh, et al., Simultaneous estimation of atorvastatin and its two metabolites from human plasma by ESI-LC-MS/MS, Drug Test. Anal. 3 (6) (2011) 352-362.

[18] M. Hermann, H. Christensen, J.L. Reubsaet, Determination of atorvastatin and metabolites in human plasma with solid-phase extraction followed by LC-tandem MS, Anal. Bioanal. Chem. 382 (5) (2005) 1242-1249.

[19] R.V. Nirogi, et al., Simultaneous quantification of atorvastatin and active metabolites in human plasma by liquid chromatography-tandem mass spectrometry using rosuvastatin as internal standard, Biomed. Chromatogr. 20 (9) (2006) 924-936.

[20] P. Partani, et al., Simultaneous quantitation of atorvastatin and its two active metabolites in human plasma by liquid chromatography/(-) electrospray tandem mass spectrometry, J. Pharm. Anal. 4 (1) (2014) 26-36.

[21] J. Wang, et al., Liquid chromatography-tandem mass spectrometry assay for the simultaneous quantification of simvastatin, lovastatin, atorvastatin, and their major metabolites in human plasma, J. Chromatogr. B: Analyt. Technol. Biomed. Life Sci. 983-984 (2015) 18-25. 